\title{
INCIDENCE OF CANINE PARVOVIRUS INFECTION OF DOGS IN ANDHRA PRADESH
}

\author{
G. D. KUMARI*, R. N. RAMANI PUSHPA, K. V. SUBRAMANYAM ${ }^{1}$ \\ T. SRINIVAS RAO ${ }^{2} A N D$ K. SATHEESH ${ }^{3}$ \\ Department of Veterinary Microbiology \\ NTR College of Veterinary Science, Gannavaram-521 102 \\ Andhra Pradesh, India
}

\begin{abstract}
The present study was conducted on the incidence studies of the canine parvovirus (CPV) infection from different parts of Andhra Pradesh, India. A total of three hundred and forty two $(n=342)$ canine parvovirus suspected clinical faecal samples of different age group of dogs from both vaccinated and non-vaccinated animals were collected. The faecal samples were preliminarily screened by haemagglutination assay and further confirmation by employing polymerase chain reaction (PCR). Dogs of age group below four months were more susceptible for CPV infection at a higher rate (77.59\%) and were predominantly seen in males. PCR technique was found to be more sensitive in confirming the CPV infection (68.42\%) than haemagglutination assay (20.67\%).
\end{abstract}

Key words: Canine parvovirus (CPV), Enteritis, Haemagglutination assay, Incidence, Polymerase chain reaction

Canine parvovirus enteritis was first reported in USA (Eugster and Nain, 1977), but the identification of the causative virus was first documented as CPV-2 in Canada in June, 1978 (Kelly, 1978; Appel et al., 1979). Canine parvovirus infection is one of the devastating disease of viral etiology affecting all age group of dogs and most commonly its occurrence is seen in pups below eight weeks age group causing nearly 90 percent mortality. In acute form of disease condition it is characterised by vomitions, haemorrhagic enteritis with foul odour, dehydration finally leading to death if associated with myocarditis. In the myocarditis form of CPV-2 infection, the clinical signs may or may not be evident and pups may die sudden without any signs

*Corresponding Author

${ }^{1}$ Department of Veterinary Microbiology, CVSc., Proddatur

${ }^{2}$ Department of Veterinary Public Health and Epidemiology, NTRCVSc., Gannavaram

${ }^{3}$ Department of Veterinary Pathology, NTRCVSc., Gannavaram 
(Meunier et al., 1984). The affected dogs void the viral particles in their faeces thus acting as a main source of transmission in spreading of the disease. The virus is shed during the acute phase of enteric fever and survives at least for four months in faeces and environment (Carmichael and Binn, 1981). Several outbreaks of CPV infection in India was reported by Chinchkar et al. (2006) and in southern India by Vivek et al. (2013). Screening of Canine parvovirus infection from different districts of Andhra Pradesh was carried out in this study based on age, sex and vaccination status.

\section{MATERIALS AND METHODS}

Three hundred and forty two faecal swabs from the rectum of clinically suspected dogs were collected from different districts of Andhra Pradesh. The samples were collected during the months of June, 2017 to December, 2018. Details are given in Table 1.

Three hundred and twenty seven samples were of unvaccinated status against canine parvovirus infection and only three samples were reported of being vaccinated only once and no boosters were further given. Sterile swabs were used for the collection of the faecal sample. Sorensons phosphate buffer saline $(0.2 \mathrm{M})$ having $\mathrm{pH}$ 7.0 was used as the transport media. The faecal swabs were emulsified in $1 \mathrm{~mL}$ of Sorensons phosphate buffer saline and later transferred to $1.5 \mathrm{~mL}$ centrifuge vials and centrifuged at $6000 \mathrm{rpm}$ for $15 \mathrm{~min}$. at $4^{\circ} \mathrm{C}$. All the faecal material gets settled at the bottom and supernatant was collected and preserved at $-80^{\circ} \mathrm{C}$ until use for performing haemagglutination tests and polymerase chain reaction.

Table 1. Details of faecal samples of dog collected from different districts of Andhra Pradesh of various age groups and both sexes

\begin{tabular}{clc}
\hline Sl. No. & \multicolumn{1}{c}{ Place of Collection } & Number of Samples \\
\hline 1 & Srikakulam & 14 \\
2 & Visakhapatnam & 25 \\
3 & East Godavari ( Kakinada, Rajamundry) & 52 \\
4 & West Godavari ( Tanuku, Eluru) & 19 \\
5 & Krishna ( Teaching Veterinary Clinical Complex and & 54 \\
& Super Speciality Veterinary Hospital) & \\
6 & Guntur & 44 \\
7 & Nellore & 51 \\
8 & Tirupati & 26 \\
9 & Kadapa & 14 \\
10 & Kurnool & 43 \\
\hline & Total & $\mathbf{3 4 2}$ \\
\hline
\end{tabular}


Haemagglutination assay was carried out as per Carmichael et al. (1980). Ninety microliter of the processed faecal sample was mixed with ten microliter of chloroform and placed at $4^{\circ} \mathrm{C}$ for $10 \mathrm{~min}$. Later centrifugation was carried out at $10,000 \mathrm{rpm}$ for $10 \mathrm{~min}$ and the supernatant obtained was used for haemagglutination assay using $0.8 \%$ pig erythrocytes in a 96 well $\mathrm{U}$ bottom microtitre plate.

The DNA extraction from the processed faecal sample was done by employing boiling method (Vieira et al., 2008). 100 $\mu \mathrm{L}$ of supernatant was boiled at a temperature of $96^{\circ} \mathrm{C}$ for $10 \mathrm{~min}$ and immediate snap chilling in crushed ice (Uwatoko et al., 1995). Centrifugation was performed at $13,200 \mathrm{rpm}$ for $10 \mathrm{~min}$ at $4^{\circ} \mathrm{C}$. The supernatant obtained was further diluted in distilled water at a ratio 1:5 prior to DNA amplification so as to decrease the faecal residues that may interfere in the polymerase chain reaction (Decaro et al., 2006). The VP2 capsid protein is highly immunogenic and the primer pair pCPV$2 \mathrm{ab}$ primer Forward $\left(5^{\prime}\right.$ GAAGAGTGGTTGTAAATAATT-3') Reverse (5'-CCTATATAACCAAAGTTA GTAC-3') amplify portion of VP1/VP2 gene of both CPV-2a and CPV-2b variants ( 3025-3706 nucleotide position of CPV genomic DNA) and produce an amplicon size of 681bp (Senda et al., 1995; Pereira et al., 2000).
PCR was carried out as per the method described by Panda et al. (2009). Initial denaturation at $95^{\circ} \mathrm{C}$ for 5 min followed by 30 cycles of denaturation at $94^{\circ} \mathrm{C}$ for 30 seconds, annealing at $55^{\circ} \mathrm{C}$ for $2 \mathrm{~min}$, extension $72^{\circ} \mathrm{C}$ for $2 \mathrm{~min}$ and final extension $72^{\circ} \mathrm{C}$ for $4 \mathrm{~min}$.

The amplified products were analysed on $1.5 \%$ agarose with ethidium bromide and performed gel electrophoresis in $1 \mathrm{X}$ tris acetate buffer and observed in a Gel Doc (Bio-rad, USA ).

\section{RESULTS}

A total of 342 samples were screened by haemagglutination assay of which 71 (20.76\%) samples had a HA titre varying from 1:32 to 1:512. Eighty one faecal samples had a titre ranging from 1:2 to 1:16 and remaining 213 could not haemagglutinate the swine $\mathrm{RBC}$ and were negative for HA test. The incidence of the disease was highest in dogs of age group 6 weeks to 4 months $(77.59 \%)$, followed by 4 months - 1year $(46.42 \%)$ and was comparatively lesser in adult dogs (Table 2).

Canine parvovirus enteritis was predominantly noticed in males $(77.56 \%)$ when compared to females $(53.73 \%)$ and high incidence of CPV infection was recorded in non-vaccinated dogs than the vaccinated ones (Table 3). 
Table 2. Occurrence of canine parvovirus in different age groups of dogs

\begin{tabular}{lcccc}
\hline S.No & Age group & $\begin{array}{c}\text { Number of } \\
\text { samples obtained }\end{array}$ & $\begin{array}{c}\text { Positive by } \\
\text { PCR }\end{array}$ & $\begin{array}{c}\text { \% of positivity by } \\
\text { PCR }\end{array}$ \\
\hline 1 & 6 weeks - 4 months & 241 & 187 & 77.59 \\
2 & 4 months - 1 year & 84 & 39 & 46.42 \\
3 & Above 1 year & 17 & 6 & 35.29 \\
\hline
\end{tabular}

Table 3. Details of occurrence of canine parvovirus based on sex and vaccination status of dogs

\begin{tabular}{llcccc}
\hline S.No & Status & \multicolumn{2}{c}{$\begin{array}{c}\text { Number of samples } \\
\text { obtained }\end{array}$} & \multicolumn{2}{c}{ Positive by PCR } \\
\cline { 3 - 6 } & & Male & Female & Male & Female \\
\hline 1 & Vaccinated & 2 & 1 & $2(100 \%)$ & $1(100 \%)$ \\
2 & Non- vaccinated & 205 & 134 & $159(77.56)$ & $72(53.73 \%)$ \\
\hline
\end{tabular}

Table 4. Details of occurrence of canine parvovirus in different districts of Andhra Pradesh based on PCR Assay

\begin{tabular}{llcc}
\hline S.No & \multicolumn{1}{c}{ District } & $\begin{array}{c}\text { Number of samples } \\
\text { collected }\end{array}$ & $\begin{array}{c}\text { No. of samples } \\
\text { positive by PCR assay }\end{array}$ \\
\hline 1 & Srikakulam & 14 & $10(71.42 \%)$ \\
2 & Visakhapatnam & 25 & $20(83.33 \%)$ \\
3 & East Godavari & 52 & $49(94.23 \%)$ \\
& (Kakinada, Rajamundry) & & \\
4 & West Godavari & 19 & $10(52.63 \%)$ \\
& ( Tanuku, Eluru) & & \\
5 & Krishna ( Teaching Veterinary & 54 & $39(72.22 \%)$ \\
& Clinical Complex and Super & & \\
& Specialty Veterinary Hospital) & & $35(79.54 \%)$ \\
6 & Guntur & 44 & $9(17.64 \%)$ \\
7 & Nellore & 51 & $15(57.69 \%)$ \\
8 & Tirupati & 26 & $12(85.71 \%)$ \\
9 & Kadapa & 14 & $35(81.39 \%)$ \\
10 & Kurnool & 43 & $\mathbf{2 3 4}(\mathbf{6 8 . 4 2 \%})$ \\
\hline & Total & $\mathbf{3 4 2}$ & \\
\hline
\end{tabular}


The occurrence of canine parvovirus in Andhra Pradesh was assayed by employing polymerase chain reaction. The infection was present in almost all the districts screened with highest percentage of infection in East Godavari (94.23\%) and less percentage of infection in Nellore (17.64\%) (Table 4).

\section{DISCUSSION}

In the present study the incidence of the disease was reported in dogs of age group 6 weeks to 4 months (77.59\%) at a higher range when compared to dogs of age group 4 months and above one year. Predisposing factors like increased intestinal epithelial turnover due to change in the microflora, weaning process and declining maternal antibodies level may be the reason for increased incidence of CPV in young pups (Stepita et al., 2013). Similar findings were reported by Mohanraj et al. (2010), Parthiban et al. (2010), Vivek et al. (2013) and $\mathrm{Xu}$ et al. (2013).

Canine parvovirus enteritis was predominantly noticed in males $(77.77 \%)$ when compared to females $(54.07 \%)$ and high incidence of CPV infection was recorded in non-vaccinated dogs conferring that the vaccines currently in use were protecting the dogs from CPV infection

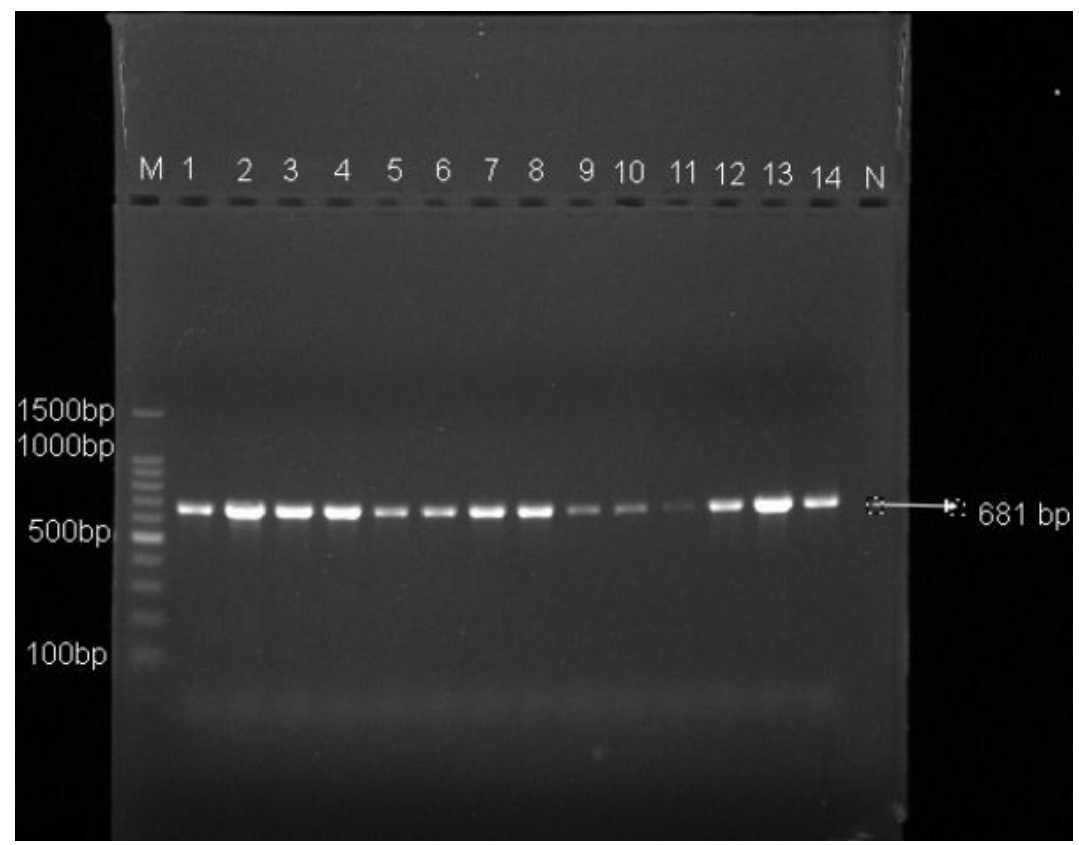

M - 100 bp ladder, Lane 1 to 14 - Positive samples from suspected clinical faecal samples, N- Negative faecal sample of healthy dog

Fig. 1. Screening of canine parvovirus infection of faecal samples of dogs by Polymerase chain reaction 
(Touihri et al., 2009; Nandi et al., 2010). However, CPV infection was also reported in few cases of vaccinated dogs which may be due to other reasons of vaccine failure like improper maintenance of cold chain.

HA is a simple and rapid test in detecting the CPV infection. The viral HA titres usually range from 128 to 10,240 between post infection days of 4 and 7 , and later the virions tend to cease in the faeces from seventh day onwards. The haemagglutinating activity has a lower sensitivity which might be due to the presence of antibodies binding to the virions in the lumen of intestine of infected dogs thus inhibiting haemagglutination assay. Initial preliminary screening of canine parvo infection by HA was economical but can detect only when high concentrations of virus is voided in the faeces. All infected dogs may not necessarily exhibit clinical manifestations but they may shed the virions in faeces only during the acute phase of enteric fever and show signiûcant rise in the serum antibody titers (Stann et al., 1984). HA has few disadvantages like continuous source of swine RBC and need to check specificity of low titre samples with haemagglutination inhibition assay.

Out of 342 samples, 234 (68.42\%) samples yielded an amplification product size of $681 \mathrm{bp}$. Polymerase chain reaction is considered as most sensitive in detecting the parvo virions as it can even detect low concentrations of virus in the sample. In the present study though the samples were collected with clear clinical signs suggestive of CPV, HA test was able to detect only 71 $(20.76 \%)$ samples and PCR proved to be highly sensitive with a percentage of 67.83 . Similar conclusions were drawn by Akbar et al. (2015) where they also compared the efficacy of two most commonly used diagnostic tests for CPV i.e., haemagglutination assay (HA) and polymerase chain reaction (PCR). Fifty fecal samples from dogs suggestive of parvovirus enteritis were collected and on performing HA, the test was able to detect CPV antigen in 35 samples, 32 samples tested highly positive with titers $>128,3$ tested weakly positive with titers ranging from 32 to 64 and 15 were negative (titers $<16$ ). Using PCR, 39 samples were found positive including 6 HA-negative samples. Thirty percent of dogs presenting bloody diarrhoea did not show infection by HA. It is concluded here that specificity and sensitivity of PCR detection is nonsignificantly higher $(\mathrm{P}>0.05)$ than $\mathrm{HA}$. These findings have confirmed that HA test could be employed for the preliminary screening of the agent in field because of its less cost and rapid results but negative results from HA tests of suspected cases should be confirmed through molecular methods. Several serological and molecular diagnostic assays were developed for quick confirmation of the CPV disease and they have been prompt, reliable and precisive (Decaro et al., 2005). 
Incidence is high in animal shelters, pet stores, breeding kennels. Nosocomial infection plays a vital role in transmission of virus from infected to healthy dogs due to improper sanitization measures taken in the hospital premices in disposal of voided faeces containing parvovirus. All age group of dogs are susceptible to get the infection but predominantly the virus tends to grow in young growing puppies of age group 6 weeks to 4 months old.

CPV a sturdy virus, its successful control of the disease can be implemented with judicious use of the vaccines against CPV. Public awareness programmes should be implemented for vaccinations to pet animals

\section{REFERENCES}

Akbar A, Asif A, Sajid U, Hajra Q, Abdul SS et al., 2015. Comparison between haemaglutination test and polymerase chain reaction for diagnosis of canine parvovirus infection. Openaccess J Vet, 3: $5-8$

Appel MJ Scott FW and Carmichael LE, 1979. Isolation and immunization studies of a canine parvo-like virus from dogs with hemorrhagic enteritis. Vet Rec, 105: 156159

Carmichael LE and Binn LN, 1981.New enteric viruses in the dog. Adv Vet Sci Comp Med, 25: $1-37$

Carmichael LE, Joubert JC and Pollock RVH, 1980. Haemagglutination by canine parvovirus: Serological studies and diagnostic applications. Am J Vet Res, 41: 784-791 for protection against the disease as in the present study maximum incidence of disease was observed in non-vaccinated and irregularly vaccinated dogs. Proper sanitation and disinfection measures should be practised especially by the pet shop owners at places like kennels, breeding management areas to ensure free of CPV presence to stop the indiscriminate spread of the disease to healthy ones.

\section{ACKNOWLEDGEMENTS}

The authors are thankful to the Associate Dean, NTR CVSc, Gannavaram, SVVU, Tirupati for providing the facilities to carry out the work.

Chinchkar SR, Subramanian BM, Rao NH, Rangarajan PN, Thiagarajan D et al., 2006. Analysis of VP2 gene sequences of canine parvovirus isolates in India. Arch Virol, 151: $1881-1887$

Decaro N, Elia G, Martella V, Campolo M, Desario C et al., 2006. Characterisation of the canine parvovirus type 2 variants using minor groove binder probe technology. J Virol Methods, 133: 92-99

Decaro N, Elia G, Martella V, Desario C, Sante $\mathrm{R}$ et al., 2005. A real time PCR assay for rapid detection and quantitation of canine parvovirus type 2 DNA in the faeces of dogs. Vet Microbio, 105: 19-28

Eugster AK and Nain C, 1977. Diarrhoea in puppies: parvoviruses-like demonstrated in their faeces. Southwest Vet, 30: 59-60

Kelly WR 1978. An enteric disease of dogs 
resembling feline panleukopenia. Aust Vet J, 54: 593

Meunier PC, Cooper BJ and Appel MJ, 1984 Experimental viral myocarditis: parvoviral infection of neonatal pups. Vet Pathol, 21(5): 509-515

Mohanraj J, Mukhopadhyay HK, Thanislass J, Antony PX and Pillai RM, 2010. Isolation, molecular characterization and phylogenetic analysis of canine parvovirus. Infect Genet Evol, 10: 1237-1241

Nandi S, Anbazhagan R and Kumar M, 2010. Molecular characterisation of nucleotide sequence analysis of canine parvovirus strains in vaccines in India. Vet Ital, 46(1): 69-81

Panda D, Patra RC, Nandi S and Swarup D, 2009. Antigenic characterization of canine parvovirus by polymerase chain reaction. Indian J Anim Sci, 79 (9): 876-879

Parthiban S, Mukhopadhyay HK, Antony PX and Pillai RM, 2010. Epidemiology of canine parvovirus enteritis in pet dogs in puducherry (India). Anim Sci Report, 4(3): 98-102

Pereira CAD, Monezi T, Mehnert DU, D'Angelo M, Durigon EL et al., 2000. Molecular characterization of canine parvovirus in Brazil by polymerase chain reaction assay. Vet Microbiol, 75: 127-133

Senda M, Parrish CP, Harasawa R, Gamoh K, Muramatsu M et al., 1995. Detection by PCR of wild type canine parvovirus which contaminates dog vaccines. J Clin Microbiol, 33: 110-113
Stann SE, DiGiacomo RF, Giddens WE and Evermann JF, 1984. Clinical and pathological features of parvoviral diarrhoea in dogs. J Am Vet Med Assoc, 185: 651654

Stepita ME, Bain MJ and Kass PH, 2013. Frequency of CPV Infection in vaccinated puppies that attended puppy socialization classes, J Am Anim Hosp Asso, 49: 95100

Touihri L, Bouzid I, Daoud R, Desario C, Goulli AF et al., 2009. Molecular characterization of canine parvovirus-2 variants circulating in Tunisia. Virus Genes, 38(2): 249-258

Uwatoko K, Sunairi M, Nakajima M and Yamaura K, 1995. Rapid method utilizing the polymerase chain reaction for detection of CPV in feaces of diarrhoeic dogs. Vet Microbiol, 43: 315-323

Vieira MJ, Silva E, Oliveira J, Vieira AL, Decaro N et al., 2008. Canine parvovirus 2 c infection in central Portugal. J Vet Diagn Invest, 20: 488-491

Vivek Srinivas VM, Mukhopadhyay HK, Thanislass J, Antony PX and Pillai RM, 2013. Molecular epidemiology of canine parvovirus in southern India. Vet World, 6(10): 744-749

Xu J, Guo HC, Wei YQ, Shu L, Wang J et al., 2013. Phylogenetic analysis of canine parvovirus isolates from Sichuan and Gansu provinces of China in 2011. Transbound Emerg Dis, 62(1): 91-95 